Cuestiones de sociología

ISSN: 2346-8904

publicaciones@fahce.unlp.edu.ar

Universidad Nacional de La Plata

Argentina

\title{
Beliera, Anabel Angélica (2019). Lo sindical en su multiplicidad. Trabajo, profesiones y afectos en el hospital
}

\author{
Malleville, Sofia \\ Beliera, Anabel Angélica (2019). Lo sindical en su multiplicidad. Trabajo, profesiones y afectos en el \\ hospital \\ Cuestiones de sociología, núm. 22, 2020 \\ Universidad Nacional de La Plata, Argentina \\ DOI: https://doi.org/10.24215/23468904e098
}

Atribución no comercial compartir igual (CC BY-NC-SA) 4.0 


\section{Beliera, Anabel Angélica (2019). Lo sindical en su multiplicidad. Trabajo, profesiones y afectos en el hospital}

Sofia Malleville

DOI: https://doi.org/10.24215/23468904e098

Comisión de Investigaciones Cientificas de la Provincia

de Buenos Aires (CIC-PBA) Laboratorio de Estudios

en Sociología y Economia del Trabajo - Instituto de

Investigaciones en Humanidades y Ciencias Sociales

(LESET-IdIHCS), Argentina

mallevillesofia@gmail.com

Pensar lo sindical y hacerlo desde una perspectiva etnográfica en un espacio concreto como es un hospital del interior de nuestro país es, sin duda, una mirada novedosa para el estudio de las organizaciones sindicales en ámbitos estatales. El libro titulado Lo sindical en su multiplicidad. Trabajo, profesiones y afectos en el hospital publicado en 2019 por la Dra. Anabel Beliera ${ }^{1}$ analiza el entramado de experiencias sindicales que tuvieron lugar en el Hospital Provincial Neuquén Dr. Castro Rendón (HPN) entre los años 2005 y 2016.

En este libro se propone desbordar el análisis de las organizaciones sindicales a partir de sus marcos institucionales y plantea una nueva mirada que contempla las experiencias laborales, las relaciones interpersonales, los afectos, los compromisos morales y las identidades profesionales para comprender la participación sindical de las personas y los grupos. Puntualmente, en el transcurso de los cinco capítulos que conforman el libro, se analizan cuatro organizaciones gremiales presentes en el hospital de mayor complejidad de la provincia de Neuquén: dos agrupaciones que competían por la conducción de la Junta Interna (JI) de la Asociación de Trabajadores Estatales (ATE) -listas Verde Morada y Violeta Negra-, el sindicato de profesionales de la salud pública neuquina (SiProSaPuNE) y, por último, el recientemente conformado Sindicato de Enfermeros de Neuquén (SEN).

Con el correr de las páginas encontramos que la mirada etnográfica no solo está presente como una decisión metodológica que antecede al desarrollo de la investigación, sino que implica una concepción y una práctica que le permite a la investigadora poner en suspenso sus certezas y ser receptiva a los sentidos que los propios actores le imprimen a lo sindical. La presencia prolongada en el campo, la posibilidad de compartir actividades gremiales y otros espacios de sociabilidad derivaron en dos descentramientos teóricometodológicos presentados en la introducción del libro.

El primero de ellos supone pasar del estudio de una acción de protesta específica, como fue la huelga de 2005, a los entramados cotidianos del HPN. En el hospital, si bien la identidad "trabajadores estatales" posibilitaba la oposición al gobierno provincial, esa homogeneidad se perdía en el cotidiano donde florecían múltiples segmentaciones. Por otra parte, el conflicto adquiría ciertas particularidades puesto que al brindar un servicio esencial para la comunidad como es la salud, la conflictividad no podía medirse únicamente por la cantidad de días de paro y/o huelgas registradas.

El segundo descentramiento se inspira en los aportes de la antropología política y supone correrse del análisis de las organizaciones sindicales en sí mismas para comprender lo sindical a partir de las experiencias y sentidos que le imprimen los propios actores. El libro no busca definir previamente los sindicatos como organizaciones delimitadas, con contornos precisos, sino que se propone analizar la yuxtaposición de experiencias en un espacio donde conviven sindicatos con una pluralidad de lógicas de construcción gremial. 
Esta investigación fue también, como lo expresa su autora, una experiencia sensitiva, que se evidencia al leer el libro. Esta apuesta teórico-metodológica se vislumbra ya desde el primer capítulo en donde el lector puede adentrarse en la dinámica cotidiana del HPN a partir de la descripción densa y la incorporación de otros recursos como mapas, fotografías, afiches, entre otros. Esta reconstrucción ayuda a sumergirse en la experiencia del trabajo en el ámbito estatal, conocer el entramado político bajo la hegemonía del Movimiento Popular Neuquino y el conflicto en un espacio que forma parte del sistema de salud pública de una provincia con gran movilización popular.

A partir del capítulo dos nos adentramos específicamente en las distintas formas de construcción gremial en el hospital. En primer lugar, la autora analiza la Lista Verde Morada de ATE que condujo la JI durante diez años seguidos (del 2003 al 2013). En esta agrupación, las actividades gremiales, la militancia y la construcción de demandas se articulaban con otros espacios de sociabilidad tanto dentro como fuera del espacio laboral. Compartir comidas y bebidas, organizar torneos de truco y fútbol, asistir a fiestas los fines de semanas, entre otras acciones permitían la construcción de vínculos interpersonales que se forjaban en ese cotidiano compartido y le imprimían a la construcción gremial un gran componente afectivo y lúdico, basado en la contención grupal y el cuidado mutuo. Esta forma de construcción permitió organizar sindicalmente al amplio segmento de trabajadores "no profesionales" y alterar parcialmente su subordinación frente a los "profesionales" del hospital.

En el capítulo tres se analiza la experiencia sindical de la otra agrupación que competía en la JI de ATE: la Lista Violeta Negra. Esta lista de filiación trotskista condujo la Junta Interna entre los años 2013 y 2015, hasta que en 2016 la Lista Verde Morada volvió al poder. En este capítulo se muestra cómo la experiencia sindical se expresa como una forma de mantener un programa político para la clase trabajadora. En esta agrupación lo sindical se movía en un juego de escalas: el lugar de trabajo y las disputas a nivel provincial y nacional. La construcción de la agrupación como un "grupo programático" tenía efectos prácticos en la vida de los sujetos y en las tramas de la organización. Se desarrollaban una serie de prácticas y aprendizajes respecto a la política, definidos incluso como pedagógicos. Esos procesos colectivos permitían la producción de "sujetos de la política", "referentes" que, al mismo tiempo, reorientaban sus proyectos de vida al calor de la militancia.

En la página ciento sesenta y tres nos encontramos con el capítulo titulado: "El sindicato de profesionales de la salud pública neuquina: la experiencia profesional al frente", nacido en 2005. Aquí se profundiza sobre una de las principales características de los ámbitos de salud: la convivencia de distintos grupos profesionales con diversas especialidades. En esta agrupación la dimensión profesional no era un dato contextual, sino que constituía una dimensión central ya que permitía organizar a los trabajadores, generando procesos de identificación y diferenciación con otros grupos. El estatus "profesional" habilitaba la construcción de demandas ante las autoridades gubernamentales donde se vislumbraban no sólo los pedidos por el mejoramiento de las condiciones laborales y salariales sino también sentidos en torno al ser profesional: la importancia de la formación, el saber científico, la vocación, el compromiso con la comunidad y la vida de los pacientes.

El último capítulo está dedicado a analizar la experiencia sindical de un grupo laboral históricamente subordinado como es la enfermería. El recientemente conformado Sindicato de Enfermería de Neuquén que logró, en 2016, representar a un cuarto del total de enfermeros/as de Neuquén. La autora reconstruye cómo en ese espacio las prácticas gremiales se orientaban hacia la reivindicación de ciertas demandas corporativas, pero también funcionaba como un punto de encuentro que permitía revalorizar y visibilizar sus labores y reconocerse mutuamente como profesionales de la salud. La feminización de este colectivo y las labores de cuidado permeaban el tipo de construcción del SEN. A su vez, la demanda por la profesionalización también incorporaba dimensiones estéticas y afectivas en articulación con experiencias individuales y colectivas con vistas de construir un perfil específico que permitiera tensionar las relaciones de subordinación frente a otros grupos profesionales del HPN. 
En síntesis, este libro puede definirse como un aporte al estudio del sindicalismo argentino durante la posconvertibilidad. No obstante, amplía este horizonte al incorporar, al menos, tres elementos que considero centrales. En primer lugar, permite conocer la experiencia sindical en ámbitos estatales del interior de nuestro país, escasamente analizados desde las ciencias sociales. En el análisis del HPN es posible vislumbrar cómo se superponen distintas escalas -local, provincial y nacional- y cómo, a lo largo del texto, los distintos niveles analíticos se conjugan en la explicitación de los argumentos.

En segundo lugar, abre nuevos caminos teórico-metodológicos para el estudio de otras organizaciones sindicales. Mediante análisis situados y procesuales, es posible analizar cómo los aspectos institucionales se entrecruzan con otras dimensiones de la vida de las personas. Como en todo ámbito, inclusive en los espacios políticos, el afecto, el cuidado, los imperativos morales, las disputas, las identidades profesionales, entre otras dimensiones permean las experiencias de quienes los conforman. La autora nos advierte que para poder captar la complejidad de la realidad social debemos ser receptivos a esa multiplicidad y dejarnos sorprender por los eventos que, en un primer momento, nos parecen desconocidos.

Por último, este libro desborda el estudio de la dinámica sindical en ámbitos estatales para adentrarse en la complejidad del mundo hospitalario. De esta forma, también puede ser leído con los lentes de las ciencias sociales de la salud. Permite comprender las múltiples dimensiones que intervienen en la atención y el cuidado de la salud en un espacio laboral concreto pero que forma parte de un entramado más amplio: el sistema de salud argentino. Un sistema que se caracteriza -desde hace ya varias décadas- por su elevada heterogeneidad y fragmentación tanto en términos espaciales, como políticos, administrativos y financieros.

\section{Notas}

1 Anabel Beliera es Doctora en Ciencias Sociales (UNLP), Magister en Ciencias Sociales (UNLP), Licenciada y Profesora en Sociología (UNLP). Becaria posdoctoral en el Laboratorio de Estudios en Sociología y Economía del Trabajo (IdIHCS, CONICET-UNLP). Docente de la Facultad de Humanidades y Ciencias de la Educación (UNLP).

\section{BY-NC-SA}

